\title{
Use of Ruthenium/Alumina as a Convenient Catalyst for Copper-Free Sonogashira Coupling Reactions
}

\author{
Soyoung Park, Min Kim, Dong Hyun Koo, Sukbok Chang* \\ Center for Molecular Design and Synthesis (CMDS), Department of Chemistry and School of Molecular Science (BK21), \\ Korea Advanced Institute of Science and Technology, Daejeon 305-701, Korea \\ Fax: (+82)-42-869-2810, e-mail: sbchang@kaist.ac.kr
}

Received: June 21, 2004; Accepted: August 23, 2004

Supporting Information for this article is available on the WWW under http://asc.wiley-vch.de.

Abstract: It has been found that a new and practical catalyst system of ruthenium-supported on alumina carries out copper-free Sonogashira coupling reactions with high efficiency over a wide range of substrates under mild and convenient conditions.

Keywords: alkynes; $\mathrm{C}-\mathrm{C}$ bond formation; copperfree Sonogashira reaction; heterogeneous catalysis; ruthenium
Alkynylation reactions of aryl and alkenyl (pseudo)halides have been developed as one of the most useful synthetic methods for the preparation of acetylene derivatives in such diverse areas as organic synthesis, materials science, pharmaceutical and fine chemical industries. ${ }^{[1]}$ The couplings are carried out most frequently by palladium catalysts combined with a copper cocatalyst in an amine, which was originally reported in $1975 .{ }^{[2]} \mathrm{Al}-$ though several modified protocols have been revealed, such as copper-free ${ }^{[3]}$ heterogeneous,${ }^{[4]}$ or bimetallic systems ${ }^{[5]}$ there is still a need to develop more practical and convenient catalytic systems that can be applied to a broader range of substrates. During the course of our studies on the development of metal-catalyzed, efficient organic transformations, we have focused on the synthetic utility of ruthenium catalysis. ${ }^{[6]}$ Whereas supported ruthenium systems can be conveniently prepared, their use as a catalyst is rather limited, in most cases, to the areas of either oxidation or hydrogenation reactions. ${ }^{[7]}$ Recently, however, we have demonstrated that a heterogeneous $\mathrm{Ru}$ /alumina catalyst system performs $\mathrm{C}-\mathrm{C}$ bond forming reactions such as olefination (Heck reactions) and Suzuki-Miyaura cross-couplings with high efficiency and selectivity. ${ }^{[8]}$ Described herein are our latest studies on the preparation of supported ruthenium catalysts and their applications to alkynylation reactions.

At the outset of our studies, we prepared a number of supported ruthenium metal systems starting from $\mathrm{RuCl}_{3}$ $x \mathrm{H}_{2} \mathrm{O}$ as precursor with a slight modification of the reported procedures ${ }^{[9]}$ Reduction of the metal precursors and subsequent immobilization of the resultant ruthenium(0) metal particles on a range of supports were carried out either by a solution phase method or by a calcination hydrogenation procedure, and their activities were examined in a test reaction of 4-iodoacetophenone with phenylacetylene (Table 1). Loaded metal contents and their average sizes were measured by using inductively coupled plasma (ICP) analysis and transmission electron microscopic (TEM) images, respectively. Metal contents on the supports were in the range of 2.2$8.5 \mathrm{wt} \%$, and ruthenium nanoparticles were uniformly dispersed on the supports with an average diameter of $2.3-10 \mathrm{~nm}$, which varied depending on the supports employed.

It was found that the nature and structure of the supporting materials play a crucial role in the catalytic activ-

Table 1. Catalytic activity of various supported Ru catalysts in alkynylation reaction. ${ }^{[a]}$

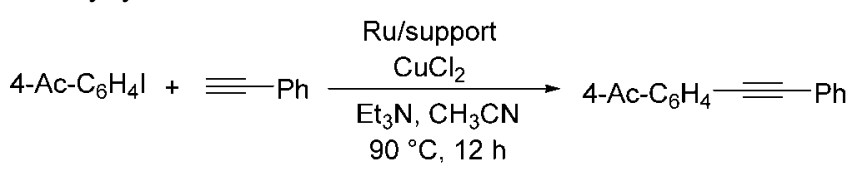

\begin{tabular}{|c|c|c|}
\hline Entry & Support (wt \% $)^{[\mathrm{b}]}$ & Yield $[\%]^{[b}$ \\
\hline 1 & carbon $(5.0)$ & 72 \\
\hline 2 & MCM-48 (8.5) & 13 \\
\hline 3 & CMK-5 (2.9) & 14 \\
\hline 4 & $\mathrm{MgO}(2.2)$ & 7.1 \\
\hline 5 & $\mathrm{TiO}_{2}(3.5)$ & 13 \\
\hline $6^{[\mathrm{c}]}$ & Montmo K10 (3.4) & 8.0 \\
\hline 7 & $\mathrm{Al}_{2} \mathrm{O}_{3}(5.0)$ & 97 \\
\hline $8^{[\mathrm{d}]}$ & $\mathrm{Al}_{2} \mathrm{O}_{3}(5.0)$ & 70 \\
\hline
\end{tabular}

[a] Reaction conditions: 4-iodoacetophenone $(0.5 \mathrm{mmol})$, phenylacetylene $(1.0 \mathrm{mmol})$, Ru/support $(5 \mathrm{~mol} \%)$, $\mathrm{CuCl}_{2}(10 \mathrm{~mol} \%)$, and triethylamine $(1.0 \mathrm{mmol})$ in $\mathrm{CH}_{3}$ $\mathrm{CN}(1.0 \mathrm{~mL})$.

${ }^{\text {b] }}$ NMR yields based on an internal standard (anisole).

[c] Montmorillonite K10.

[d] In the absence of copper cocatalyst. 
ity of the corresponding impregnated ruthenium catalysts. For example, while conversion of the reaction was over $70 \%$ within $12 \mathrm{~h}$ in the presence of $\mathrm{CuCl}_{2}$ cocatalyst when ruthenium on activated carbon was used as a catalyst ( $5 \mathrm{~mol} \%)$ in acetonitrile (entry 1$)$, a change of the template to silica-based materials such as MCM$48^{[10]}$ resulted in much poorer activity under otherwise identical conditions (entry 2). Acetonitrile was the solvent of choice and other solvents were less satisfactory in the reaction. It is interesting that among the similar carbon-based materials, use of mesoporous materials such as CMK- $5^{[11]}$ brought about significantly lower activity compared to an active charcoal template (compare entries 1 and 3). ${ }^{[12]}$ Ruthenium catalysts supported on inorganic oxides such as $\mathrm{MgO}^{[13]}$ and $\mathrm{TiO}_{2}^{[14]}$ displayed low reactivity on the alkynylation (entries 4 and 5, respectively). In addition, use of montmorillonite $\mathrm{K} 10^{[15]}$ as a support did not improve the catalytic activity of impregnated ruthenium catalyst (entry 6). On the other hand, alumina turned out to be most effective among the various supports investigated. The reaction took place quantitatively with the use of a commercially available Ru/alumina catalyst (entry 7). The high activity of the $\mathrm{Ru}$ /alumina catalyst system permitted the reaction to proceed in acceptable yields even in the absence of copper cocatalysts (entry 8). It should be mentioned that this represents the first example of a heterogeneous ruthenium catalyst system for the Sonogashira coupling reactions without the need of copper cocatalysts. ${ }^{[16]}$ When longer reaction times were allowed, a complete conversion was achieved even in the copper-free ruthenium system (vide infra). On the other hand, no conversion was observed when only alumina was employed even in large excess, implying that no background reaction took place with the alumina support. It turned out that triethylamine was the most efficient base among those examined thus giving a full conversion, and others were inferior: pyrrolidine (46\%), $\mathrm{Cs}_{2} \mathrm{CO}_{3}(50 \%)$, and 2,6lutidine $(<5 \%)$.

A wide array of substrates was subjected to the optimized reaction conditions (Table 2 ). Using $\mathrm{Ru}$ /alumina as a catalyst in the absence of the copper cocatalyst, moderate to excellent product yields were obtained from the coupling reactions. The electronic nature of the alkynyl substituents has little influence on the efficiency of the couplings (entries 1-4) although those with electron-donating groups retarded slightly the reaction, requiring higher reaction temperatures to obtain satisfactory results (entry 5). Electronic effects of aryl iodides on the coupling efficiency were also negligible as in the cases of the acetylene counterparts. As a result, good to excellent yields were obtained from the reactions of phenylacetylene with various aryl iodides regardless the electronic nature of electrophilic reagents (entries 6-8). It was observed that a conjugated enyne was also readily participated in the reaction (entry 9). When 2-chloro-5-iodopyridine was used, only the iodo
Table 2. Ru-catalyzed copper-free Sonogashira reactions. ${ }^{[a]}$

\begin{tabular}{|c|c|c|c|}
\hline \multicolumn{2}{|c|}{$\mathrm{R}=+\mathrm{I}-\mathrm{Ar}+\mathrm{Et}_{3} \mathrm{~N}$} & \multicolumn{2}{|c|}{$\begin{array}{l}\underset{\mathrm{Ru} / \mathrm{Al}_{2} \mathrm{O}_{3}}{\mathrm{CH}_{3} \mathrm{CN}} \\
90^{\circ} \mathrm{C}, 24 \mathrm{~h}\end{array} \mathrm{R}=\mathrm{Ar}$} \\
\hline Entry & $\mathrm{R}$ & $\mathrm{Ar}$ & Yield $[\%]^{[b]}$ \\
\hline 1 & $\mathrm{C}_{6} \mathrm{H}_{5}$ & $\mathrm{C}_{6} \mathrm{H}_{5}$ & 85 \\
\hline 2 & $\mathrm{C}_{6} \mathrm{H}_{5}$ & 4-Ac- $\mathrm{C}_{6} \mathrm{H}_{4}$ & 85 \\
\hline 3 & $4-\mathrm{Br}-\mathrm{C}_{6} \mathrm{H}_{4}$ & $4-\mathrm{Ac}^{-} \mathrm{C}_{6} \mathrm{H}_{4}$ & 79 \\
\hline 4 & 4- $\mathrm{CF}_{3}-\mathrm{C}_{6} \mathrm{H}_{4}$ & 4-Ac- $\mathrm{C}_{6} \mathrm{H}_{4}$ & 87 \\
\hline $5^{[c]}$ & 4-PhO- $\mathrm{C}_{6} \mathrm{H}_{4}$ & $4-\mathrm{Ac}^{-} \mathrm{C}_{6} \mathrm{H}_{4}$ & 71 \\
\hline 6 & $\mathrm{C}_{6} \mathrm{H}_{5}$ & $4-\mathrm{O}_{2} \mathrm{~N}-\mathrm{C}_{6} \mathrm{H}_{4}$ & 86 \\
\hline 7 & $\mathrm{C}_{6} \mathrm{H}_{5}$ & 4-EtO ${ }_{2} \mathrm{C}-\mathrm{C}_{6} \mathrm{H}_{4}$ & 98 \\
\hline 8 & $\mathrm{C}_{6} \mathrm{H}_{5}$ & 2-Me- $\mathrm{C}_{6} \mathrm{H}_{4}$ & 92 \\
\hline 9 & 1-cyclohexenyl & $4-\mathrm{Ac}-\mathrm{C}_{6} \mathrm{H}_{4}$ & 60 \\
\hline 10 & $\mathrm{C}_{6} \mathrm{H}_{5}$ & & 60 \\
\hline $11^{[\mathrm{cc}]}$ & 3-thienyl & $4-\mathrm{Ac}-\mathrm{C}_{6} \mathrm{H}_{4}$ & 74 \\
\hline $12^{[c]}$ & 3-pyridyl & 4-Ac- $\mathrm{C}_{6} \mathrm{H}_{4}$ & 97 \\
\hline 13 & $\mathrm{C}_{6} \mathrm{H}_{5}$ & 2-naphthyl & 66 \\
\hline 14 & $(i-\mathrm{Pr})_{3} \mathrm{Si}$ & $4-\mathrm{Ac}^{-} \mathrm{C}_{6} \mathrm{H}_{4}$ & 91 \\
\hline
\end{tabular}

[a] Reaction conditions: aryl iodide $(0.5 \mathrm{mmol})$, alkyne $(1.0 \mathrm{mmol}), \mathrm{Ru} / \mathrm{Al}_{2} \mathrm{O}_{3}(5 \mathrm{wt} \%, 5 \mathrm{~mol} \%)$, and triethylamine $(1.0 \mathrm{mmol})$ in $\mathrm{CH}_{3} \mathrm{CN}(1.0 \mathrm{~mL})$.

[b] Isolated yield.

[c] Run at $110^{\circ} \mathrm{C}$.

group was selectively coupled with phenylacetylene to give the corresponding alkynylchloropyridine adduct in moderate yield (entry 10). Heteroaromatic acetylenes were coupled with aryl iodides in good to excellent yields albeit at higher reaction temperatures (entries 11 and 12). A silyl-substituted acetylene was also smoothly coupled with 4-iodoacetophenone in good yield (entry 14). It is worthy of remark that the reaction conditions are highly convenient so that a simple aqueous work-up after the reactions provides the desired products with a high purity ( $>95 \%,{ }^{1} \mathrm{H}$ NMR) after removal of excess volatile starting materials, thus making the present procedure highly practical. The coupling reactions could be readily scaled up to gram scales while still maintaining the same efficiency as on the depicted scale of Table 2. Moreover, the heterogeneous catalyst can be recovered quantitatively after the coupling, and the catalytic activity of thus recovered material remained almost unchanged in the second cycle reaction. ${ }^{[17]}$

In summary, we have demonstrated that ruthenium supported on alumina can be used as a convenient and practical catalyst system for the Sonogashira reactions 
between terminal alkynes and iodoarenes. It was found that efficiency of the reaction was influenced significantly by the nature and structure of metal supports. The heterogeneous catalyst exhibits high activity and selectivity over a range of substrates allowing the coupling reactions to proceed efficiently even in the absence of copper cocatalysts.

\section{Experimental Section}

\section{Typical Procedure for Alkynylation of Iodoarenes}

To a solution of 4-iodoacetophenone $(123 \mathrm{mg}, 0.50 \mathrm{mmol})$ in acetonitrile $(1.0 \mathrm{~mL})$ was added phenylacetylene $(102 \mathrm{mg}$, $1.0 \mathrm{mmol}), \mathrm{Et}_{3} \mathrm{~N}$ (102 mg, $\left.1.0 \mathrm{mmol}\right)$, and $\mathrm{Ru} / \mathrm{Al}_{2} \mathrm{O}_{3}(5 \mathrm{wt} \%$, $52 \mathrm{mg}, 0.025 \mathrm{mmol})$. The reaction mixture was stirred for $24 \mathrm{~h}$ at $90^{\circ} \mathrm{C}$ and then was diluted with EtOAc $(10 \mathrm{~mL})$ followed by water $(10 \mathrm{~mL})$. The organic layer was separated, dried over anhydrous $\mathrm{MgSO}_{4}$, and filtered. After removal of organic solvent under reduced pressure, the residue was purified by flash column chromatography (ethyl acetate/hexane, 1:20) to give the desired product, 4-(phenylethynyl)acetophenone; yield: $94 \mathrm{mg}(85 \%)$.

\section{Acknowledgements}

This research was supported by Korea Science \& Engineering Foundation (R02-2003-000-10075-0) through the Basic Research Program.

\section{References and Notes}

[1] a) K. Sonogashira, in: Metal-Catalyzed Cross-Coupling Reactions, (Eds.: F. Diederich, P. J. Stang), Wiley-VCH, Weinheim, 1998, pp. 203-229; b) K. Sonogashira, in: Handbook of Organopalladium Chemistry for Organic Synthesis, Vol. 1, (Ed.: E. Negishi), Wiley-Interscience, New York, 2002, pp. 493-529.

[2] a) K. Sonogashira, Y. Tohda, N. Hagihara, Tetrahedron Lett. 1975, 16, 4467-4470; b) L. Cassar, J. Organomet. Chem. 1975, 93, 253-257; c) H. A. Dieck, F. R. Heck, J. Organomet. Chem. 1975, 93, 259-263.

[3] For selected examples, see: a) J.-P. Ganêt, E. Blart, M. Savignac, Synlett 1992, 715-717; b) M. Alami, F. Ferri, G. Linstrumelle, Tetrahedron Lett. 1993, 34, 6403-6406; c) V. P. W. Böhm, W. A. Herrmann, Eur. J. Org. Chem. 2000, 3679-3681; d) X. Fu, S. Zhang, J. Yin, D. P. Schumacher, Tetrahedron Lett. 2002, 43, 6673-6676; e) T. Fukuyama, M. Shinmen, S. Nishitani, M. Sato, I. Ryu, Org. Lett. 2002, 4, 1691-1694; f) D. A. Alonso, C. Nájera, M. C. Pacheco, Adv. Synth. Catal. 2003, 345, 1146-1158.

[4] a) B. M. Choudary, S. Madhi, N. S. Chowdari, M. L. Kantam, B. Sreedhar, J. Am. Chem. Soc. 2002, 124, 14127-14136; b) R. G. Heidenreich, K. Köhler, J. G. E. Krauter, J. Pietsch, Synlett 2002, 1118-1122; c) M. R.
Buchmeiser, Bioorg. Med. Chem. Lett. 2002, 12, 18371840; d) L. Djakovitch, P. Rollet, Tetrahedron Lett. 2004, 45, 1367-1370.

[5] S. U. Son, Y. Jang, J. Park, H. B. Na, H. M. Park, H. J. Yun, J. Lee, T. Hyeon, J. Am. Chem. Soc. 2004, 126, 5026-5027.

[6] a) Y. Na, S. Chang, Org. Lett. 2000, 2, 1887-1889; b) M. Lee, S. Chang, Tetrahedron Lett. 2000, 41, 7507-7510; c) M. Lee, S. Ko, S. Chang, J. Am. Chem. Soc. 2000, 122, 12011-12012; d) S. Chang, Y. Na, E. Choi, S. Kim, Org. Lett. 2001, 3, 2089-2091; e) S. H. Yang, S. Chang, Org. Lett. 2001, 3, 4209-4211; f) S. Ko, Y. Na, S. Chang, J. Am. Chem. Soc. 2002, 124, 750-751; g) E. Choi, C. Lee, Y. Na, S. Chang, Org. Lett. 2002, 4, 2369-2371; h) S. Ko, H. Han, S. Chang, Org. Lett. 2003, 5, 26872690; i) S. Ko, C. Lee, M.-G. Choi, Y. Na, S. Chang, J. Org. Chem. 2003, 68, 1607-1610.

[7] For selected recent examples, see: a) G. C. Bond, A. D. Hooper, Appl. Catal. A: Gen. 2000, 191, 69-81; b) A. Miyazaki, I. Balint, K.-i. Aika, Y. Nakano, J. Catal. 2001, 204, 364-371; c) K. Yamaguchi, N. Mizuno, Angew. Chem. Int. Ed. 2003, 42, 1480-1483; d) G. Marconi, P. Pertici, C. Evangelisti, A. M. Caporusso, G. Vitulli, G. Capannelli, M. Hoang, T. W. Turney, J. Organomet. Chem. 2004, 689, 639-646.

[8] Y. Na, S. Park, S. B. Han, H. Han, S. Ko, S. Chang, J. Am. Chem. Soc. 2004, 126, 250-258.

[9] For details of the preparative procedures, see the Supporting Information.

[10] For examples of the use of MCM-48 as a support material, see: a) M. Eswaramoorthy, Neeraj, C. N. R. Rao, Chem. Commun. 1998, 615-616; b) C. D. Nunes, M. Pillinger, A. A. Valente, J. Rocha, A. D. Lopes, I. S. Goncalves, Eur. J. Inorg. Chem. 2003, 3870-3877; c) M. Chatterjee, F. Y. Zhao, Y. Ikushima, Adv. Synth. Catal. 2004, 346, 459-466.

[11] H. Darmstadt, C. Roy, S. Kaliaguine, T.-W. Kim, R. Ryoo, Chem. Mater. 2003, 15, 3300-3307.

[12] For a recent review on the effects of porosity on the catalytic activity, see: D. E. De Vos, M. Dams, B. F. Sels, P. A. Jacobs, Chem. Rev. 2002, 102, 3615-3640.

[13] Y. L. Wei, Y. M. Wang, J. H. Zhu, Z. Y. Wu, Adv. Mater. 2003, 15, 1943-1945.

[14] a) C. Elmasides, D. I. Kondarides, W. Grünert, X. E. Verykios, J. Phys. Chem. B. 1999, 103, 5227-5239; b) H. Kanai, Y. Ikeda, S. Imamura, Appl. Catal. A 2003, 247, 185191.

[15] M. A. Martinez-Lorente, P. Battioni, W. Kleemiss, J. F. Bartoli, D. Mansuy, J. Mol. Catal. A: Chem. 1996, 113, 343-353.

[16] During the preparation of this manuscript, it has been reported that a combinatorial approach leads to that $\mathrm{RuCl}_{2}$ (1-Me-4-i-Pr- $\left.\mathrm{C}_{6} \mathrm{H}_{4}\right)\left(\mathrm{PPh}_{3}\right)$ catalyzes an alkynylation reaction in the presence of $\mathrm{CuI}$ albeit with a modest yield: $\mathrm{S}$. Garbacia, R. Touzani, O. Lavastre, J. Comb. Chem. 2004, 6, 297-300.

[17] A typical procedure of recycling experiments is described in the Supporting Information. 